\section{DECAPSULATION OF THE KIDNEYS IN BRIGHT'S DISEASE.}

BY

\section{T. H. SANDERSON-WELLS, M.B.E., M.D.LOND.} F:R.C.S.EDIN.

SURGEON, WEYMOUTH AND DISTRICT HOSPITAL, WEYMOUTH.

IT is usually difficult to state when the Sirst definite step towards any new procedure has taken place. Often the idea develops in the minds of more than one person acting from different points of view. It seems to me this has been the case with regard to decapsulation of the kidneys as a treatment for nephritis. The pioneers were Harrison, Edebohls, Israel, and Pousson, with many others, the two first mentioned apparently taking precedence. 'The history is as follows: The late Reginald Harrison in 1896 published in the Lancet three cases of acute nephritis cured by incision or puncture of the kidney for relief of tension: Later in the same year he contributed an article to the British Medical Journal proposing incision of the kidney for: (1) Acute nephritis with tenderness on pressure in the loins; (2) suppression of urine; and (3) for slow disappearance of casts. In 1901 he published in the British Medical Journal three cases in which he had incised the kidneys to relieve tension. These publications appeared to have attracted little notice; certainly they caused no great stir, and his suggestions were not generally followed.

Edebohls, in reviewing the clinical records of the patients on whom he had performed nephropexy by reflecting the caspule and stitching it to the lumbar muscles in the manner which is associated with his name, found that he had five times operated on patients suffering from chronic nephritis. He remarked that in three of these patients there was a "complete and permanent disappearance of albumin and casts," and "restoration to perfect and enduring health." Weighing this in his mind, he came across a sixth case in which both the kidneys were loose and the patient was suffering from chronic nephritis. On January 10th, 1898, he reflected the capsule and fixed the kidneys in this case, and claims that this was the first operation undertaken on the kidneys with the deliberate object of curing Bright's disease. In May of 1901 he went a step further and performed decapsulation, the kidney being in place, for the sole purpose of curing chronic nephritis, and later in the same year he published an article in the New York Medical Record reviewing 18 cases of chronic Bright's disease in which he had in the earlier cases reflected and later excised the capsule of the kidney, with the result that 8 of the patients were cured. He stated that after ten days there was an increased flow of urine.

It is interesting to note that these two authorities had a different object in view. Harrison incised or punctured the kidney for relief of tension, in the hope that it would lead to the absorption of the inflammatory products, allow the passage of urine down the tubules, restore the blood supply, and revive the tubular epithelium. The object of Edebohls was temporarily to relieve tension, but by bringing the kidney substance into contact with vascular tissue to increase its blood supply and allow a steady progress towards cure. They both agreed that the fibrous capsule formed an impassable barrier, one to expansion, the other to vascularization. These views were attacked on several grounds.

Physiologists pointed out: (1) That the renal arteries are end arteries and terminal; (2) that the blood supply from the capsule is insignificant; (3) that renal tissue once destroyed does not regenerate; and (4) that chronic nephritis is the local expression of a general disease, and a cure must remove the cause. Experiments were made on animals and the following results demonstrated: (1) That a new capsule was formed in a few weeks thicker and denser than the normal capsule; (2) that there were fewer vessels in the new than the old. Injections were made into (1) the renal arteries and (2) the aorta with the renal arteries tied. The general opinion as the result of these experiments was that there was but slight communication.

Stursburg, however, found on injecting into the aorta with the renal artery tied that the injection penetrated even to the papillae. Martini found new vessels in the new capsule and also that dogs survived an operation upon the renal vessels if the kidneys had been previously decapsu. lated, but died if this had not been done. Siter in 1913, in the Journal of the American Association of Genito. Urinary Surgery, gave results of experiments on cats and dogs. The kidney decapsulated and wrapped in omentum increased in size, new capsule formed immediately, new collateral circulation in ten days. This new collateral circulation, he held, was sufficient to allow the kidney to functionate when the renal vessels were tied. This many of his colleagues held to be impossible.

\section{Pathological Reports.}

Edebohls, in 1904, admitted the conflicting experimental evidence, but claimed that Dr. Larkin had demonstrated the existence of vascularization in two kidneys four months after decapsulation. Boyd and Beattie, in the Edinburgh Medical Journal in 1905, reported on the kidneys of a patient who died four months after decap. sulation, and found the capsule vascular and containing vessels which appeared to anastomose with the vessels in the superficial part of the cortex of the kidney; they were, however, in doubt as to whether these vessels were more than those normally found between the renal and perirenal tissues ruptured by decapsulation. Gatti, in 1908 , performed double decapsulation. The patient died twenty months later; the result of necropsy was that a capsule thicker than usual, with only a few blood vessels, was found. Boinet, in 1905, reported on the kidneys of a patient who died twenty-eight months after double decapsulation, that the new thick capsule was but little vascularized.

From the physiological and pathological standpoints the outlook therefore appears disappointing. From the clinical aspect, however, the result is quite different. Case after case is reported, mostly after months of exhaustive medical treatment of every description, including tappings after operations undertaken in extremis, in nraemia, eclampsia, suppression of urine, or when complet $1 y$ waterlogged, with astonishing results. The uraemic patient is restored to consciousness, the suppressed urine commences to flow, the oedema disappears. Patients apparently doomed have returned to work, many have subsequently passed an examination by the highest authorities and have been pronounced completely cured.

Edebohls, in his manual of the surgical treatment of Bright's disease, published in 1904, reports seventy-two cases. Seventeen are claimed as completely cured; many who were extremely ill were livnng in comparative health and comfort; nine cases operated on at death's door weie alive and well. Sir Thomas Horder, in the British Medical Journal of November 13th, 1920, reports four cases with two cures demonstrated by most exhaustive examination, the other two being improved. He states his opinion as follows: "There is a clinical type of nephritis in which decapsulation becomes a definite indication and promises satisfactory results." Frank Kidd, in the BRITISH Medical Journat of March 12th, 1921, reports four cases, "one of which four years after operation appears to be perfectly well ; the others improved in varying degree."

Crawford Burns, in the Edinburgh Medical Journal of September, 1916, reports a case, a female child, aged 6, operated on by Mr. Miles. She was oedematous; the vulvae distended; both kidneys were decapsulated at one operation. A fortnight after the operation urine became copious and dropsy disappeared. Operation was in February; she got up on March 25th and went home on April 8th, "lively and in good health." In the same journal of February, 1921, there are two cases published by Boyd: Case 1: A miner, aged 41, with sivelling of the abdomen and legs, and oedema of lungs, was in a critical condition; operation was performed in January and the patient discharged on February 3rd. After a short time at home he returned to work; he has since worked uninterruptedly for three years. Case 2: A lad admitted for Bright's disease, later became uraemic with convulsions. When operated upon a fatal termination appeared imminent; five months later he enjoyed apparently good health.

\section{Case.}

The case I have to report is that of a man, aged 30, admitted to the Weymouth and District Hospital on September 24th 1920. He had been on active service in the navy. Swelling of the feet and legs was first noticed in January, 1919. He was about that time in Haslar Hospital for five months. 
On admission the legs and abdomen were swollen; he oomplained of weakness and shortness of breath. As regards the urine, specific gravity was 1020, the reaction was neutral, and it was full of albumin. The patient was treated during September and October on medical lines-jalap, diuretics of vaptember and October on medical lines-jalap, diuretics of vacying sorts, citrate and acetate of potash, diuretin, etc. Later he was given hot-air baths, pilocarpin in $\frac{1}{8}$-grain doses. He had a vegetable and salt-free diet. Fluid was cut down to two pints and subsequently less daily. The urine varied between per 1,000 Esbach, with lesser variations, were recorded.

In November his condition was such that he could not lie down. His legs were enormously distended, his abdominal wall was oedematous, he had ascites and oedema of the lungs. On November 10th Southey's tubes were put into the right leg and $46 \mathrm{oz}$. were dra $46 \mathrm{oz}$. Were drained away; on November 13th tubes were put 20 th other southey's tubes were introduced and further drainage resulted.

As a result he improved. On November 22nd the note is: "Lung condition relieved, but dropsy still obstinate. Urine about 50 oz albumin 12 parts Hsbach per 1,000 but has been down to one-half part per 1,000. In December, 1920, he was given hot-air baths daily, and at intervals dry cupping to the loins. The diet was milk and vegetables. The urine had increased to from $40 \mathrm{oz}$. to $60 \mathrm{oz}$. On December 14th, 15th, and 16th the albumin was. 8 parts per 1,000 Esbach, bat has been down to ous half part per 1,C00. During January this treatment was continued and varying drugs were tried without any result. The oedema continued about the same. The patient could not lie down. Towards the end of January I saw him and made half a dozen incisions into his legs, which were then wrapped up in fomentations; 16 pints of fluid were quickly caught and this continued for some weeks. The dropsy diminished considerably, but by the end of January the note says: "Dropsy returned after the incisions had ceased draining; general condition much the same."

At this stage I proposed an operation to him, which he gladly At this stage I proposed an operation to him, which he gladly
accepted, and on April 29th I decapsulated the right kidney, accepted, and on April 29th I decapsulated the right kidney, which was very much enlarged, soft, friable, and pale in colour. Esbach measurement was one-quarter part per 1,000. On May 15th the patient's general condition was much improved. The oedema had disappeared from the legs except the ankles, and completely from the arms. The legs were being massaged daily, and on the 28 th the oedema had all gone from the legs, including the ankles. The legs were daily bandaged with soft crêpe bandages.

During this time I was away on my holiday, and on my return I found the patient walking about. With difficulty I persuaded him to have the left kidney decapsulated. Before consenting he went home, and returned for the operation on consenting he went hom all an arranged date free from all oedema, but with his urine loaded with albumin. I decided, however, to proceed, and the left kidney was treated in the same way as the right. On June of urine was $50 \mathrm{oz}$. daily. The patient subsequently left the of urine was $50 \mathrm{oz}$. daily.
hospital and returned home.

My attention was drawn to this procedure by an nnusually sad case, an only child who was suffering from chronic nephritis. She was completely waterlogged, and the parents were anxious for anything possible to be done. I saw her several times in consultation with a friend and we decided against operation. After watching this case and studying the literature more thoroughly I now believe an operation would have been her best chance, as she died after a painful and prolonged struggle.

The published cases demonstrate that success is possible even in extremis, and some remarkably complete recoveries are recorded. Although the physiological and pathological findings are adverse, the clinical results prove that from the patient's point of view the outcome is often satisfactory. My patient is quite settled on this point. Moreover, he is probably characteristic of many in that, though not com. pletely cured and possibly doomed eventually to die of the disease, the operation has been justified by the result.

The operation deserves consideration under two conditions :

1. As an emergency in eclampsia, uraemia, suppression of urine, etc. The more desperate the extremity the more certainly it should be discussed, and cases have been snatched from apparently impending dissolution.

2. In chronic cases, when medical treatment has failed after a thorough trial. In both the above classes the beart and arteries should be reasonably sound, which probably means that most success will be obtained in the first half of life.

DURING the last ten years the Japanese population in the United States has increased by 53.8 per cent., or more than all the other nationalities who have entered that country.

\section{THE PASTEURIZATION OF THE MILK SUPPLY}

$\mathrm{BY}$

S. G. MOORE, M.D., D.P.H.,

MILROX LECTURER, 1916; MEDICAL OFFICER OF HEALTH HUDDERSFIELD.

LARGELY as the result of the persistent efforts of one of her citizens, New York has had a safe millk supply for the past five years. It is illegal there for milk to be sold for human consumption unless $(a)$ it is from a herd of cows found by the tuberculin test to be free from tuberculosis (b) contains less than 30,000 micro-organisms per cubic centimetre; and $(c)$ is free from Bacillus coli in each of two samples $=10 \mathrm{c.cm}$. each, or else has been pasteurized. Other milk may only be sold for commercial purposes, not directly to the public for food.

Milk may be classitied thus : (1) Fresh pure raw milk: A living fluid, clean, free from tubercle bacilli and all other pathogenic organisms. (2) Pasteurized: The freshest and purest obtainable, heated to $145^{\circ}-160^{\circ} \mathrm{F}$. for twenty to thirty minutes in the same vessels in which it will be sealed and retailed. (3) Sterilized: Heated to boiling point for longer or shorter periods, (4) Dried: A form of millk in powder, obtained either by pouring ordinary milk over slowly revolving steam-heated cylinders or spraying it into a chamber against a current of hot dry air. (5) Last and worst, the form as vended among the public day by day.

The first grade is the ideal. It is scarce and costly; the total quantity available in England is insufficient for a single large town. Pasteurized milk offers the best prospect of a safe and satisfactory supply.

Sterilized milk is objected to from varying standpoints. Perhaps the fact that many persons dislike its cooked taste so much that they will not consume it is the most important. Again, it-is alleged that infants fed on it develop scurvy, rickets, or Barlow's disease. These allegations are founded upon the conception that essential food factors are destroyed in the process of sterilization.

Dried milk has substantial advantages over ordinary milk in that it lreeps indefinitely if properly stored, can readily be transported for long distances, can easily be stored, and is safe. The investigation carried out for the Minister of Health by Dr. Francis Coutts established that. On the other hand, the product does not permit of perfect reconstitution by the addition of water, however great may be the care exercised in the process. Not infrequently the butter fat appears in small globules rather than as cream. From time to time close examination reveals that the powder has a faint sub-rancid odour. On only one occasion during an experience of its use extending over twelve years has the writer found this condition so pronounced as to call for rejection of the supply. The makers readily and willingly replaced it, and expressed regret at the occurrence. It is costly. To some palates its taste is not agreeable. The "vitamin content" calls for investigation.

'The process of pasteurization has made a place for itself in the United States of America which will repay careful examination. Reference has been made to the position in New York City. Similar statutes are in force in Chicago and in Cleveland, while in 95 per cent. of the cities of over 100,000 in the States pasteurization is approved and enjoined, though not enforced. 'The process calls for definition. A considerable proportion of mill sold in the ordinary way in large English cities is put through an operation called pasteurization, in order to delay souring, and so avoid the heavy losses entailed by milk becoming unmarketable, especially in lot weather.

There are various makes of apparatus on sale for this purpose, many originating in Denmark.* Milk flows through them in a continuous stream, entering at room temperature, passing through, or between, steam-heated coils, or chambers, and emerging at a temperature of $170^{\circ} \mathrm{F}$. There need be no doubt that they adequately serve their purpose from the commercial point of view. But it is objectionable to call such apparatus " pasteurizers." The essential characteristic of the process devised by Pasteur to secure sterilization without alteration of essential

* A sample recently collected by the writer from such a machine. perature of $170^{\circ} \mathrm{F}$. at its point of emergence. It yielded abundant
growth on culture. 